\title{
Analysis of Variation Trends in Precipitation in an Upstream Catchment of Huai River
}

\author{
Peng Shi, ${ }^{1,2}$ Xinxin $\mathrm{Ma}^{2}$ Xi Chen, ${ }^{1,2}$ Simin Qu, ${ }^{1,2}$ and Zhicai Zhang ${ }^{2}$ \\ ${ }^{1}$ State Key Laboratory of Hydrology-Water Resources and Hydraulic Engineering, Nanjing 210098, China \\ ${ }^{2}$ College of Water Resources and Hydrology, Hohai University, Nanjing 210098, China
}

Correspondence should be addressed to Peng Shi; ship@hhu.edu.cn

Received 8 December 2012; Accepted 12 February 2013

Academic Editor: Yongping Li

Copyright (C) 2013 Peng Shi et al. This is an open access article distributed under the Creative Commons Attribution License, which permits unrestricted use, distribution, and reproduction in any medium, provided the original work is properly cited.

\begin{abstract}
We analyzed the variation trends in precipitation according to the observed data in the Shaying River catchment, upstream of the Huai River from 1951 to 2010, using the linear regression method and Mann-Kendall test. Further study was made by introducing $R / S$ analysis, and the corresponding Hurst Exponent was estimated to predict the future trends of rainfall. The results suggested that the changing trends in precipitation for different time series in the whole catchment were relatively complex and not obvious. The annual precipitation showed a slightly increasing trend over the past 60 years, and in the future it would be antipersistent. For the 38 rainfall stations, the trends in spring and autumn precipitation time series were mostly negative; on the contrary, the trends in summer and winter were mostly positive. The results also indicated that the annual precipitation series showed positive trends in the northern region and negative trends in the southern region. Moreover, the relationships of $H-Z$ and $H-\beta$ of the 38 stations were analyzed. The results indicated that the greater the absolute values of $Z$ the stronger the persistent nature. Meanwhile, for most of the $H$ values were close to 0.5 , the randomness of the future trends could not be ignored.
\end{abstract}

\section{Introduction}

Climate variability and human activities have become major concerns among societies and governments, as global warming arising from the anthropogenic-driven emissions of greenhouse gases has emerged in the last two decades and other water-related issues rendering the necessity of studying changes in hydrological processes $[1,2]$. Knowledge of trends and variations of current and historical hydro-climatological variables is pertinent to the future development and sustainable management of water resources of a given region [3]. It is convinced that precipitation is one of the most important factors influencing water resources because changes in precipitation patterns may lead to floods or droughts in different areas. Understanding the spatial and temporal variability of precipitation series is of profound significance from both the scientific and practical point of view [4-7]. However, precipitation is not uniform and varies considerably from place to place and time to time, even on small scales, hence it is particularly hard to gauge the precipitation changes.
So far, many studies have focused on the analysis of precipitation variability at different temporal scales (from daily to annual) and in different parts of the world. Mosmann et al. [8] examined summer precipitation series of mainland Spain in 333 rainfall stations from 1961 to 1990 and found a statistically significant trend in wide areas. Cislaghi et al. [9] analyzed the long daily rainfall data in Italy. There results showed that the annual precipitation exhibited a negative trend in the first half of 20th century, with a subsequent positive trend in northern Italy. Conversely, the dataset for southern Italy displayed only a negative trend. Coulibaly [10] described spatial and temporal variability in Canadian seasonal precipitation for the period 1900-2000 and gained further insights into the dynamic relationship between the seasonal precipitation modes of climate variability in the Northern Hemisphere. Liu et al. [11] studied annual precipitation during 1961-2006 in Yellow River Basin, China. The results revealed that the precipitation possessed longitude zonality and had no clearly linear relationship with the latitude, most of the precipitation stations showed a decreasing trend in the basin. Ellouze et al. [12] checked 
the spatial and temporal variability of rainfall characteristics over Southern Tunisia. Rainfall variability is shown to be dependent on seasonal conditions. Spatial patterns of shorter rainfall series (annual) are governed mainly by topography and coastal influence. Nastos and Zerefos [13] found out the spatial and temporal variability of the dry and wet spells in Greece, during the period 1958-2007. Kumar and Jain [1] investigated seasonal and annual rainfall and rainy days at five stations in Kashmir Valley to decipher rainfall trends. Afzal et al. [14] summarized trends and variability in daily precipitation from 28 weather stations with up to 80 years in Scotland.

Besides, there are a number of ongoing techniques to measure trends in hydrological and climatological time series. The Mann-Kendall (M-K) test has been widely used as an effective method to evaluate a presence of a statistically significant trend [15-17]. Tabari and Talaee [7] determined the annual and seasonal precipitation trends of 41 stations in Iran for the period 1966-2005 using the M-K test, the Sen's slope estimator, and the linear regression method. Wang et al. [18] reviewed the hydro-climatic trends for the lower reach of the Shiyang River Basin in the NW China using the wavelet analysis and the $\mathrm{M}-\mathrm{K}$ test. In order to identify the optimal combination of the hydro-climatic data series in the discrete wavelet transform (DWT), the results from DWT were tested by the M-K test. Yang et al. [19] concluded temperature and precipitation trends in the Zhangweinan River Basin, based on monthly mean data for 53 years, from 1957 to 2009. They applied Mann-Kendall test method and cumulative anomaly method to analyze the long-term trends.

Another concern for precipitation change is the detection of the possible presence of long memory in the data, for example, if the change has occurred, whether and how the change persists. Hurst [20] heuristically detected the presence of long range dependence (or long memory) in the wellknown series of annual minima of the Nile River. A Hurst Exponent value $H$ between 0.5 and 1 indicates "persistent behavior," that is the time series is trending. Many researchers believe that a decrease or increase trend will tend to follow a decrease or increase for $H$ between 0.5 and 1 (e.g, $[19,21])$. Montanari et al. [22] examined six rainfall time series in various sites in Italy. However, they found a decreasing trend, though not statistically significant, in each of their records, but significant long memory in only two of them.

In Huai River basin, the majority of the previous studies in precipitation changes were focused on the whole Huai River based on sparsely observed climate data [2, 23-26]. They showed that no statistically significant trends of precipitation in the upper and middle Huai River Basins were detected at the annual scale and the trend of precipitation decreased significantly only in April. As we know, detection of changes in the precipitation and hydrological series is dependent on length and location of the observation data. In this study, the Shaying River, one of the first order tributaries in the upstream of the Huai River was selected to investigate the precipitation trends and its persistency. The linear regression method, Mann-Kendall test, and the rescaled range analysis ( $R / S$ analysis) were used for the period of 1951-2010 using data from 38 observation stations.

\section{Materials and Methods}

2.1. Study Area and Data. Shaying River, originated in the western mountainous area of Henan province, is the first tributary in the upstream of Huai River. It flows into the western of Anhui province through the central part of the Henan from northwest to southeast and falls into Huai River in the Mo River mouth of Fuyang city in Anhui province. Shaying River is located between $111.95^{\circ}$ and $114.03^{\circ} \mathrm{E}$ in longitude and $33.07^{\circ}$ and $34.42^{\circ} \mathrm{N}$ in latitude (Figure 1). The catchment area above the Luohe station is $12150 \mathrm{~km}^{2}$, and the mountainous area accounts for $75 \%$. The terrain of the catchment tilts from northwest to southeast, and plains in the southeast area were flat and open. The catchment is adjacent to the Yellow River Basin and the Yangtze River Basin and has a continental monsoon climate. The annual average temperature is within $10.7 \sim 12.9^{\circ} \mathrm{C}$ in the western mountains and within $14.5^{\circ} \mathrm{C} \sim 14.9^{\circ} \mathrm{C}$ in the eastern plains. The annual precipitation is between 650 and $1400 \mathrm{~mm}$. The annual distribution of rainfall is extremely uneven because its climate belongs to the south-north climate transition straps [27]. Nearly $42 \%$ of total rainfall concentrates on rainy season from June to September, and most between July and August.

Daily precipitation data from 38 rainfall stations in the study area were obtained to analyze the trend in annual, seasonal, and monthly scales, and the arithmetic average method was used to get catchment average precipitation. Considering the integrity and reliability of the source material, combined with observation of actual situation in the catchment, different time series in each station were selected, the longest series is 60 years (1951-2010), and the shortest series is 45 years. Thus, we have based our analysis on the period 1951-2010. The geographical location of the stations is shown in Figure 1.

\subsection{Methods}

2.2.1. Linear Regression Method. The method of linear regression is widely used in detecting and analyzing the variation trends in time series, which has an advantage that it provides a measure of significance based on the hypothesis test on the slope and also gives the magnitude of the rate of change [28]. The slope, which is the main statistical parameter drawn from the regression analysis, is the very index quantifying the trend of the temporal change in the studied period [29]. In details, positive values of the slope indicate increasing trends while negative values refer to decreasing trends. The total change during the period under observation is obtained with multiplying the slope with the number of years $[7,28,30]$.

2.2.2. Mann-Kendall Test. The Mann-Kendall test is a nonparametric test, which was highly recommended for general use by the World Meteorological Organization [31]. There are two advantages for the test. The first one is that it does not require the data to be distributed normally; the second one is its low sensitivity to abrupt break due to inhomogeneous time series [7]. According to the test, the null hypothesis $H_{0}$ states that there is no trend in the analyzed records, 


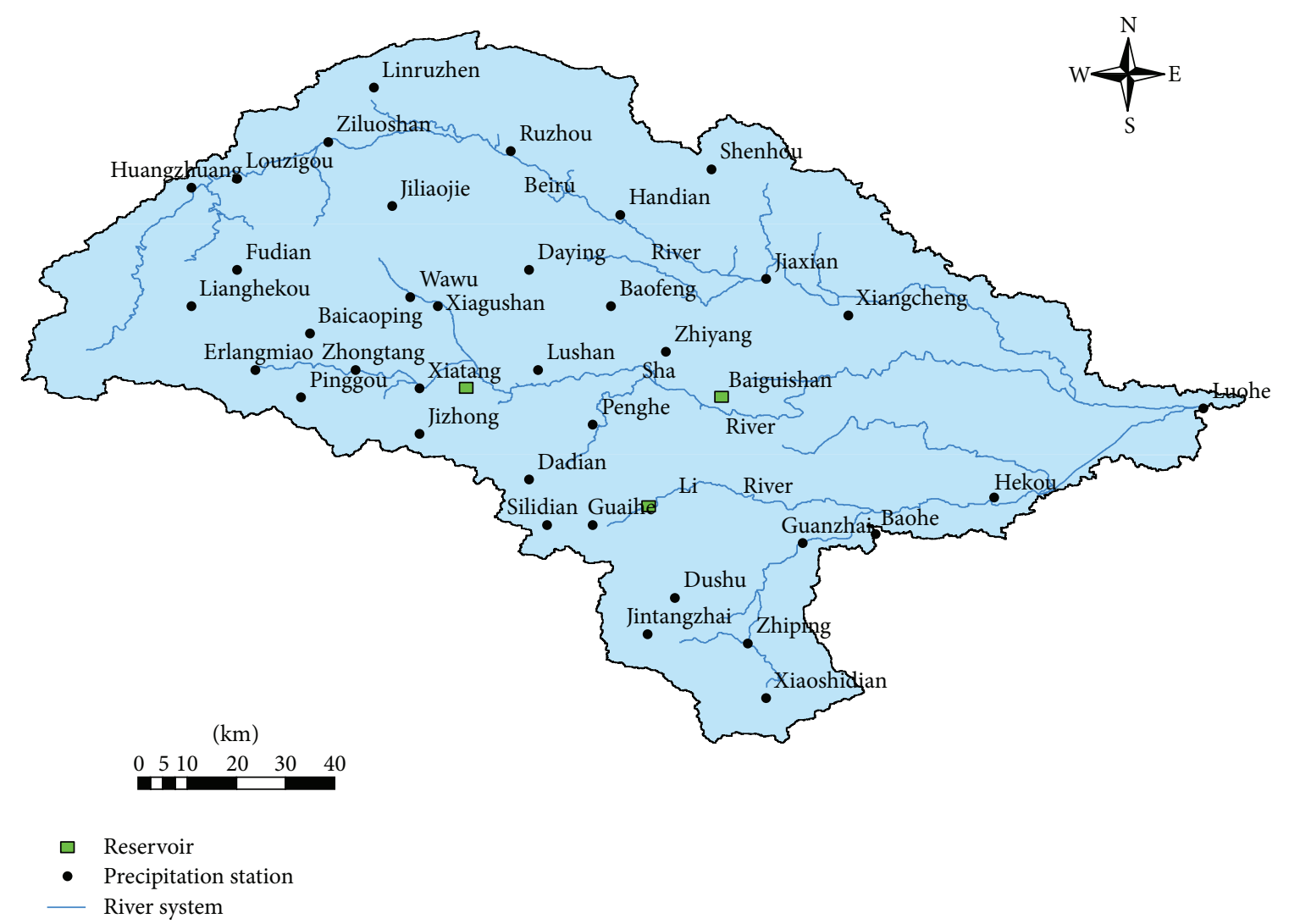

FIGURE 1: Study area and location of the gauge stations.

while the alternative hypothesis of a two-sided test is that the series displays change trend [32]. For a time series $X=$ $\left\{x_{1}, x_{2}, \ldots, x_{n}\right\}$, the test statistic, $S$, is given by

$$
\begin{gathered}
S=\sum_{i=1}^{n-1} \sum_{j=i+1}^{n} \operatorname{sign}\left(x_{j}-x_{i}\right) \\
\operatorname{sign}\left(x_{j}-x_{i}\right)= \begin{cases}1 & \text { if } x_{j}-x_{i}>0 \\
0 & \text { if } x_{j}-x_{i}=0 \\
-1 & \text { if } x_{j}-x_{i}<0\end{cases}
\end{gathered}
$$

where $n$ is the number of data points. Under the assumption that the data are independent and randomly ordered, the mean of $S$ is zero and the variance is given by [33]

$$
\operatorname{Var}(S)=\frac{n(n-1)(2 n+5)-\sum_{i=1}^{m} t_{i}\left(t_{i}-1\right)\left(2 t_{i}+5\right)}{18}
$$

where $m$ is the number of groups of tied ranks (equal observations), each with $t_{i}$ tied observations.

Kendall [33] also shows that the distribution of $S$ tends to normality as the number of observations becomes large.
In cases where the sample size $n>10$, the standard normal variable $Z$ is computed by

$$
Z= \begin{cases}\frac{(S-1)}{\sqrt{\operatorname{Var}(S)}} & S>0 \\ 0 & S=0 \\ \frac{(S+1)}{\sqrt{\operatorname{Var}(S)}} & S<0 .\end{cases}
$$

Positive values of $Z$ indicate increasing trends while negative values show decreasing trends. When testing increasing or decreasing monotonic trend at the $\alpha$ significance level, the null hypothesis was rejected for an absolute value of $Z$ greater than $Z_{1-\alpha / 2}$ obtained from the standard normal cumulative distribution tables. In this research, significance level of $\alpha=$ $0.1,0.05,0.01$ was applied, while the corresponding values of $Z_{1-\alpha / 2}$ are $1.64,1.96$, and 2.58 , respectively.

Another useful indicator is the Kendall slope $\beta$, which is used to quantify the changing trend, indicating the direction and the size of trend [19]. When $\beta>0$, it indicates an upward trend, while $\beta<0$ indicates a downward trend. The formulization of $\beta$ is as follows:

$$
\beta=\operatorname{Median}\left[\frac{x_{i}-x_{j}}{i-j}\right], \quad \forall j<i,
$$

where $1<j<i<n$. The higher the absolute value of $\beta$ the greater the degree of the change. 
2.2.3. $R / S$ Analysis. $R / S$ analysis was also called the Rescaled Range Analysis, which was the eldest and best-known method to estimate Hurst Exponent [34]. The exponent was originally proposed by Hurst [20] to analyze the time series flow data of Nile River, which was theoretically improved by Mandelbrot and Willis (1969).

The basic idea of the $R / S$ analytical method could be described as follows $[35,36]$.

For the time series of a certain physical quantity $\{x(\tau)\}(\tau=1,2, \ldots, n)$, the average value of $x(t)$ is

$$
x_{\tau}=\frac{1}{\tau} \sum_{t=1}^{\tau} x(t) .
$$

The cumulative deviation is

$$
X(t, \tau)=\sum_{t=1}^{\tau}\left(x(t)-x_{\tau}\right), \quad 1 \leq t \leq \tau .
$$

The range sequence is

$$
R(\tau)=\max _{1 \leq t \leq \tau} X(t, \tau)-\min _{1 \leq t \leq \tau} X(t, \tau) .
$$

The standard deviation sequence is

$$
S(\tau)=\sqrt{\left(\frac{1}{\tau} \sum_{t=1}^{\tau}\left(x(t)-x_{\tau}\right)^{2}\right)} .
$$

Finally they defined the nondimensional ratio $R / S$ as follows:

$$
\frac{R(\tau)}{S(\tau)}=(\alpha \tau)^{H}
$$

Hurst described $\ln (R / S)$ with $\ln \tau$ and found that the points in the data group almost lie on a straight line with perfect regularity [37]. The slope of the line is called the Hurst Exponent $(H)$. When $H=0.5$, it means that the time series is an independent random process, which indicates that the current trend will not affect the future trend. When $0.5<H<1$, it describes a dynamically persistent, or trend reinforcing series; with the greater the $H$ value, the stronger the persistent. When $0<H<0.5$, it describes an antipersistent, or a mean reverting system; the smaller the $H$ value, the stronger the antipersistent [29].

\section{Results and Discussion}

3.1. Trend Analysis by Linear Regression Method. Figure 2 showed the trends of the catchment average precipitation from 38 observation stations in time intervals of annual and seasonal scales. Since the $R^{2}$ values were small, the trends of seasonal and annual precipitation were all not significant. The analyses were just a reference in the study area. During the period between 1951 and 2010, the annual precipitation showed a slightly positive trend and a large fluctuation (Figure 2(a)). The annual precipitation increased in a rate of $0.0425 \mathrm{~mm} /$ year. Large fluctuations of the annual precipitation occurred in 1960s and late 1990s.
TABLE 1: Values of $Z$ of the M-K test, the Kendall slope $\beta$, and $H$ of the $R / S$ analysis for monthly, seasonal, and annual series.

\begin{tabular}{lccc}
\hline Time & $Z$ & $\beta(\mathrm{mm} / \mathrm{a})$ & $H$ \\
\hline January & -0.74 & -0.036 & 0.452 \\
February & 0.48 & 0.037 & 0.556 \\
March & 0.13 & 0.015 & 0.689 \\
April & -1.32 & -0.269 & 0.754 \\
May & 1.41 & 0.489 & 0.634 \\
June & 1.51 & 0.546 & 0.534 \\
July & 1.21 & 0.760 & 0.562 \\
August & -0.17 & -0.131 & 0.512 \\
September & 0.82 & 0.205 & 0.687 \\
October & -0.68 & -0.168 & 0.623 \\
November & -1.26 & -0.240 & 0.546 \\
December & -0.34 & -0.026 & 0.641 \\
Spring (3-5 month) & 0.13 & 0.077 & 0.595 \\
Summer (6-8 month) & 0.49 & 0.637 & 0.596 \\
Autumn (9-11 month) & -0.29 & -0.177 & 0.620 \\
Winter (12-2 month) & 0.03 & 0.012 & 0.560 \\
Flood season (6-9 month) & -0.08 & -0.232 & 0.595 \\
Major flood season (7-8 month) & 0.18 & 0.158 & 0.595 \\
Nonflood season (10-5 month) & -0.41 & -0.269 & 0.615 \\
Annual & 0.08 & 0.050 & 0.447 \\
\hline
\end{tabular}

The linear regression analysis was further applied to detect the seasonal trends of precipitation for the whole catchment (Figures 2(b), 2(c), 2(d), and 2(e)). During 19512010, a decreasing trend was found from the precipitation time series in spring and autumn, with the change rates of $-0.011 \mathrm{~mm} /$ year and $-0.365 \mathrm{~mm} /$ year, respectively. In summer and winter, the precipitation series had positive trends at the rates of $0.241 \mathrm{~mm} /$ year and $0.051 \mathrm{~mm} /$ year, respectively. Comparing with the change rates, we know that precipitation changes in the summer and autumn were relatively significant but they were in opposite change directions, resulting in a small change in the annual precipitation.

3.2. Mann-Kendall Test for Precipitation Trends. The MannKendall test was applied for testing the trends of the precipitation time series in different time scales of the catchment average precipitation (Table 1 ). Under the $90 \%$ significant level, the value of $Z_{1-\alpha / 2}$ equals to 1.64 . Compared with the standard normal variant $Z$ in the value of $1.64, Z$ values in Table 1 indicated that no significant trends were detected for the catchment averaged precipitation in monthly, seasonal, and annual time scales.

According to positive and negative values of $Z$ and $\beta$ in Table 1, for monthly precipitation series, six months including January, April, August, October, November, and September showed decreasing trends. The Kendall slope $\beta$ varied from $-0.026 \mathrm{~mm} /$ year in September to $-0.269 \mathrm{~mm} /$ year in April. Meanwhile, the left six months present increasing trends. These increase trends in May, June, and July were relatively more significant than those of other months. The $\beta$ values in May, June, and July were $0.490,0.546$, and $0.760 \mathrm{~mm} /$ year, 


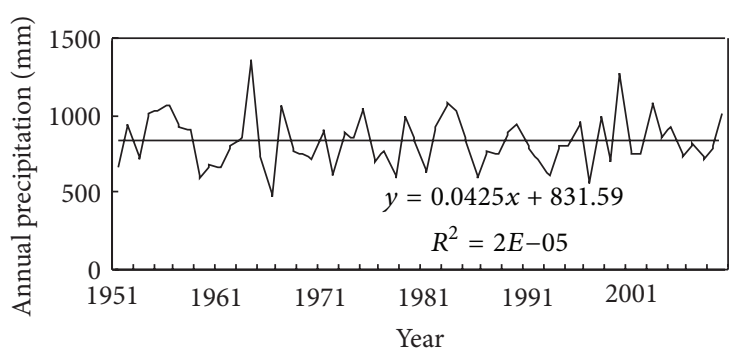

(a) Annual

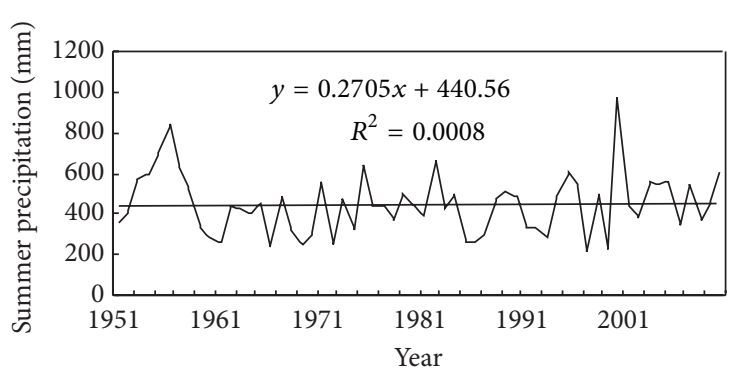

(c) Summer

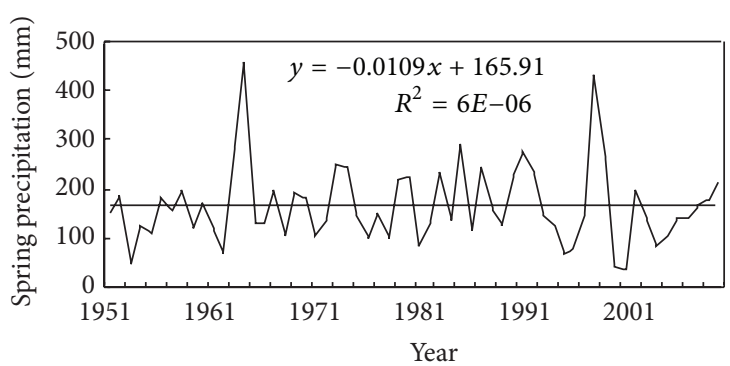

(b) Spring

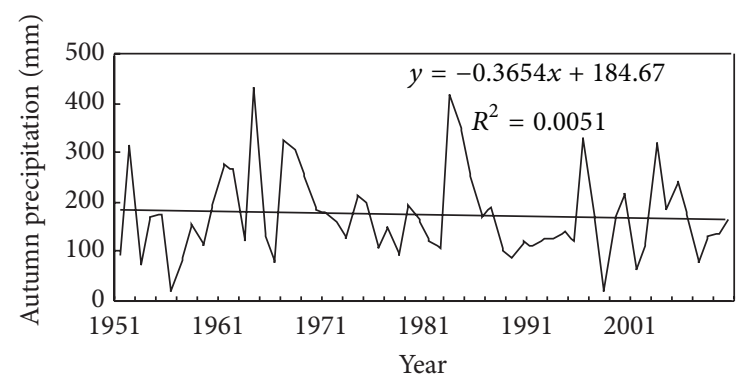

(d) Autumn

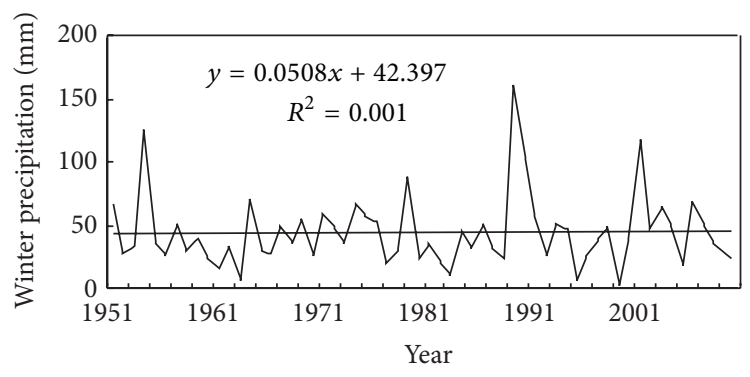

(e) winter

FIGURE 2: Trends for annual and seasonal precipitation during the period 1951-2010 by linear regression method.

respectively. For seasonal and annual precipitation series, the precipitation trends detected by $\mathrm{M}-\mathrm{K}$ test were similar to those by the linear regression analysis though the magnitude of their changes was not different. The positive trend in summer was relatively significant, with the $\beta$ value of $0.637 \mathrm{~mm} /$ year. In the major flooding season (7-8 month), the $\beta$ value was $0.158 \mathrm{~mm} /$ year.

The results of $\mathrm{M}-\mathrm{K}$ test using observed time series of individual station were shown in Table 2 and Figure 2. The number of the stations with increasing trends was almost same as that with decreasing trends in annual precipitation scale. Only three stations indicated that the trends were statistically significant. The annual precipitation in Jizhong and Zhiping stations showed increasing trends at the $90 \%$ and 99\% confidence levels, respectively, while in Lianghekou station, the decreasing trend was found at the $95 \%$ confidence level.

On the seasonal scale, the trends detected significantly at the $90 \%, 95 \%$, and 99\% confidence levels were mostly positive and these significant positive trends occurred in spring, summer, and winter. Among all 38 stations in Table 2 and Figure 2, the number of stations with positive trends in spring, summer, and winter was 1,8 , and 2 , respectively. It is found that significant positive trends for the eight stations in summer are located in the downstream of the study catchment, including Baiguishan, Baohe, Handian, Penghe, Silidian, Xiagushan, Zhaopingtai, and Zhiping. Meanwhile, only one station of Jiliaojie showed a significant negative trend for precipitation in autumn. The results also indicated that the majority of the precipitation trends in spring and autumn were negative, accounting for about $68 \%$ and $89 \%$ of the total number of stations, respectively. However, most of the trends were positive in summer and winter, accounting for $63 \%$ and $71 \%$ of the total number of stations, respectively. The increase trends in summer, particularly in the plain area of downstream station, would result in increasing flood occurrences in the study region.

Further analysis was executed in three subcatchments of the Beiru River, Sha River, and Li River in the south, middle, and north of the study catchment, respectively (Figure 1). Table 3 showed that the absolute values of statistics $Z$ were all lower than 1.64, which means no significant trends were detected by the $\mathrm{M}-\mathrm{K}$ test in the three regions for seasonal and annual series. However, the change trends presented regional 
TABLE 2: Values of $Z$ of the M-K test and the Kendall slope $\beta$ for annual and seasonal precipitation in different stations.

\begin{tabular}{|c|c|c|c|c|c|c|c|c|c|c|}
\hline \multirow{2}{*}{ Station } & \multicolumn{2}{|c|}{ Spring } & \multicolumn{2}{|c|}{ Summer } & \multicolumn{2}{|c|}{ Autumn } & \multicolumn{2}{|c|}{ Winter } & \multicolumn{2}{|c|}{ Annual } \\
\hline & $\mathrm{Z}$ & $\beta(\mathrm{mm} / \mathrm{a})$ & $\mathrm{Z}$ & $\beta(\mathrm{mm} / \mathrm{a})$ & $\mathrm{Z}$ & $\beta(\mathrm{mm} / \mathrm{a})$ & $\mathrm{Z}$ & $\beta(\mathrm{mm} / \mathrm{a})$ & $\mathrm{Z}$ & $\beta(\mathrm{mm} / \mathrm{a})$ \\
\hline Baicaoping (BCP) & -0.06 & -0.031 & 0.08 & 0.104 & -0.72 & -0.441 & -0.25 & -0.038 & -0.46 & -0.909 \\
\hline Baiguishan (BGS) & -0.39 & -0.310 & $2.34^{* *}$ & 3.016 & -1.40 & -1.017 & 1.43 & 0.195 & 0.89 & 1.199 \\
\hline Baofeng (BF) & -0.63 & -0.525 & 0.95 & 1.331 & -1.33 & -0.931 & 0.18 & 0.049 & -0.01 & -0.008 \\
\hline Baohe (BH) & -0.16 & -0.185 & $1.74^{*}$ & 3.648 & -1.30 & -1.133 & 0.68 & 0.190 & 0.82 & 2.050 \\
\hline Dadian (DD) & -0.09 & -0.027 & 0.78 & 1.411 & 0.01 & 0.000 & 0.65 & 0.114 & 0.54 & 1.071 \\
\hline Daying (DY) & -0.36 & -0.224 & 0.95 & 1.061 & -1.14 & -0.758 & 0.63 & 0.139 & 0.17 & 0.340 \\
\hline Dushu (DS) & -0.21 & -0.144 & 0.51 & 0.587 & -0.36 & -0.278 & -0.19 & -0.019 & 0.11 & 0.114 \\
\hline Erlangmiao (ElM) & -0.19 & -0.125 & -0.81 & -1.372 & -0.30 & -0.239 & 0.20 & 0.041 & -1.14 & -2.235 \\
\hline Fudian (FD) & 0.00 & 0.000 & -0.89 & -1.152 & -0.07 & -0.037 & 0.91 & 0.133 & -0.99 & -1.605 \\
\hline Guaihe $(\mathrm{GH})$ & -0.83 & -0.523 & 1.63 & 2.369 & -0.90 & -0.719 & 0.37 & 0.064 & 0.38 & 0.704 \\
\hline Guanzhai (GZ) & -1.12 & -0.686 & 0.78 & 1.278 & -1.15 & -0.941 & -0.15 & -0.054 & 0.23 & 0.355 \\
\hline Handian (HD) & -0.59 & -0.477 & $1.82^{*}$ & 2.242 & -2.17 & -1.239 & 1.05 & 0.203 & 0.99 & 1.575 \\
\hline Hekou (HK) & -0.76 & -0.536 & 1.31 & 1.712 & -0.50 & -0.334 & 0.10 & 0.028 & 0.35 & 0.830 \\
\hline Huangzhuang (HZ) & -0.80 & -0.456 & -1.26 & -1.355 & 0.27 & 0.089 & 0.30 & 0.052 & -1.48 & -1.863 \\
\hline Jizhong (JZ) & 0.96 & 0.745 & 1.55 & 2.512 & -0.83 & -0.683 & 1.14 & 0.245 & $1.69^{*}$ & 4.332 \\
\hline Jiliaojie (JLJ) & -0.85 & -0.700 & -0.58 & -0.717 & $-2.14^{* *}$ & -1.689 & 0.34 & 0.076 & -1.28 & -3.251 \\
\hline Jiaxian (JX) & 0.03 & 0.026 & -0.44 & -0.528 & -0.79 & -0.428 & 0.49 & 0.070 & -0.47 & -0.519 \\
\hline Jintangzhai (JTZ) & -0.06 & -0.034 & 1.35 & 1.721 & -0.56 & -0.423 & -0.53 & -0.089 & 0.52 & 0.885 \\
\hline Lianghekou (LHK) & -0.96 & -0.405 & -1.24 & -1.163 & -0.79 & -0.512 & -0.45 & -0.059 & $-2.13^{* *}$ & -2.384 \\
\hline Linruzhen (LRZ) & -0.62 & -0.268 & -0.67 & -0.624 & -0.12 & -0.059 & 0.83 & 0.117 & -0.70 & -0.856 \\
\hline Louzigou (LZG) & -0.78 & -0.376 & -0.88 & -0.774 & -0.41 & -0.290 & 0.24 & 0.031 & -0.93 & -1.523 \\
\hline Lushan (LS) & -0.06 & -0.048 & 0.54 & 0.736 & -0.03 & -0.017 & -0.18 & -0.043 & -0.21 & -0.412 \\
\hline Luohe (LH) & -0.83 & -0.492 & 0.25 & 0.221 & -0.57 & -0.384 & -1.08 & -0.224 & -0.98 & -1.662 \\
\hline Penghe $(\mathrm{PH})$ & -0.28 & -0.307 & $2.53^{* *}$ & 4.911 & -1.19 & -1.342 & 0.31 & 0.068 & 1.03 & 2.532 \\
\hline Pinggou (PG) & -1.58 & -2.410 & 0.59 & 1.218 & -1.48 & -1.490 & 0.17 & 0.069 & -0.37 & -1.023 \\
\hline Ruzhou (RZ) & -0.33 & -0.167 & -0.17 & -0.135 & -0.07 & -0.046 & -0.30 & -0.039 & -0.25 & -0.213 \\
\hline Shenhou (SH) & 0.16 & 0.125 & -0.84 & -1.083 & -0.22 & -0.111 & 0.57 & 0.090 & -0.82 & -1.253 \\
\hline Silidian (SLD) & -0.32 & -0.151 & $1.90^{*}$ & 3.167 & 0.18 & 0.095 & 1.24 & 0.254 & 1.14 & 2.539 \\
\hline Wawu (WW) & 0.57 & 0.315 & -0.64 & -0.868 & -0.09 & -0.032 & 0.94 & 0.166 & -0.97 & -1.436 \\
\hline Xiagushan (XGS) & 0.03 & 0.024 & $1.82^{*}$ & 3.033 & -1.39 & -1.175 & 0.15 & 0.022 & 0.90 & 1.635 \\
\hline Xiatang (XT) & 0.19 & 0.139 & 0.76 & 1.307 & 0.01 & 0.003 & 0.03 & 0.004 & 0.27 & 0.521 \\
\hline Xiaoshidian (XSD) & -0.55 & -0.257 & 0.26 & 0.466 & -1.02 & -0.700 & -0.13 & -0.027 & -0.27 & -0.549 \\
\hline Xiangcheng (XC) & -0.25 & -0.098 & -0.67 & -0.768 & -0.73 & -0.475 & -0.41 & -0.065 & -0.96 & -1.116 \\
\hline Zhaopingtai (ZPT) & 0.42 & 0.317 & $3.01^{* * *}$ & 4.444 & -0.82 & -0.726 & 0.61 & 0.153 & 1.62 & 3.347 \\
\hline Zhiping (ZP) & $2.34^{* *}$ & 2.087 & $2.20^{* *}$ & 4.200 & -0.44 & -0.347 & $4.82^{* * *}$ & 1.217 & $2.98^{* * *}$ & 7.476 \\
\hline Zhiyang (ZY) & 0.12 & 0.090 & -0.11 & -0.101 & -0.23 & -0.197 & $1.68^{*}$ & 0.292 & 0.04 & 0.027 \\
\hline Zhongtang (ZT) & 0.00 & 0.000 & 0.75 & 1.123 & -1.35 & -1.100 & 0.00 & 0.000 & 0.01 & 0.000 \\
\hline Ziluoshan (ZLS) & 0.32 & 0.114 & 0.00 & 0.000 & -0.15 & -0.105 & 1.18 & 0.165 & -0.22 & -0.289 \\
\hline
\end{tabular}

${ }^{*}$ Trends statistically significant at the $90 \%$ confidence level, ${ }^{* *}$ trends statistically significant at the $95 \%$ confidence level, ${ }^{* * *}$ trends statistically significant at the $99 \%$ confidence level.

TABLE 3: Values of $Z$ of the M-K test and the Kendall slope $\beta$ for annual and seasonal precipitation in three subcatchments.

\begin{tabular}{lcccccccccc}
\hline \multirow{2}{*}{ Subcatchments } & \multicolumn{2}{c}{ Spring } & \multicolumn{2}{c}{ Summer } & \multicolumn{2}{c}{ Autumn } & \multicolumn{2}{c}{ Winter } & \multicolumn{2}{c}{ Annual } \\
& $Z$ & $\beta$ & $Z$ & $\beta$ & $Z$ & $\beta$ & $Z$ & $\beta$ & $Z$ \\
\hline Beiru River & -0.22 & -0.150 & -0.62 & -0.602 & -0.35 & -0.202 & 0.30 & 0.046 & -0.90 \\
Sha River & 0.47 & 0.268 & 0.52 & 0.579 & -0.06 & -0.029 & 0.21 & 0.045 & 0.21 & 0.297 \\
Li River & -0.16 & -0.078 & 0.86 & 1.364 & -0.59 & -0.349 & -0.08 & -0.025 & 0.17 & 0.274 \\
\hline
\end{tabular}


TABLE 4: Values of $H$ of the $R / S$ analysis for annual and seasonal precipitation in different stations.

\begin{tabular}{|c|c|c|c|c|c|}
\hline \multirow{2}{*}{ Station } & \multicolumn{5}{|c|}{$H$} \\
\hline & Spring & Summer & Autumn & Winter & Annual \\
\hline $\mathrm{BCP}$ & 0.560 & 0.640 & 0.636 & 0.668 & 0.532 \\
\hline BGS & 0.513 & 0.572 & 0.633 & 0.658 & 0.399 \\
\hline $\mathrm{BF}$ & 0.488 & 0.612 & 0.662 & 0.714 & 0.478 \\
\hline $\mathrm{BH}$ & 0.401 & 0.529 & 0.664 & 0.558 & 0.418 \\
\hline DD & 0.659 & 0.672 & 0.673 & 0.542 & 0.338 \\
\hline DY & 0.547 & 0.648 & 0.643 & 0.666 & 0.468 \\
\hline DS & 0.499 & 0.617 & 0.610 & 0.515 & 0.485 \\
\hline ELM & 0.491 & 0.614 & 0.672 & 0.624 & 0.487 \\
\hline FD & 0.511 & 0.748 & 0.659 & 0.569 & 0.669 \\
\hline $\mathrm{GH}$ & 0.616 & 0.655 & 0.655 & 0.550 & 0.461 \\
\hline GZ & 0.511 & 0.530 & 0.588 & 0.607 & 0.401 \\
\hline HD & 0.503 & 0.651 & 0.712 & 0.547 & 0.542 \\
\hline HK & 0.461 & 0.595 & 0.678 & 0.536 & 0.430 \\
\hline $\mathrm{HZ}$ & 0.560 & 0.691 & 0.629 & 0.637 & 0.611 \\
\hline $\mathrm{JZ}$ & 0.744 & 0.629 & 0.581 & 0.653 & 0.740 \\
\hline JLJ & 0.541 & 0.736 & 0.722 & 0.690 & 0.586 \\
\hline JX & 0.572 & 0.762 & 0.609 & 0.658 & 0.609 \\
\hline JTZ & 0.501 & 0.661 & 0.554 & 0.633 & 0.540 \\
\hline LHK & 0.430 & 0.698 & 0.679 & 0.587 & 0.649 \\
\hline LRZ & 0.551 & 0.675 & 0.717 & 0.622 & 0.506 \\
\hline LZG & 0.575 & 0.609 & 0.611 & 0.576 & 0.596 \\
\hline LS & 0.614 & 0.710 & 0.712 & 0.640 & 0.587 \\
\hline LH & 0.445 & 0.557 & 0.670 & 0.678 & 0.637 \\
\hline $\mathrm{PH}$ & 0.602 & 0.649 & 0.579 & 0.502 & 0.511 \\
\hline PG & 0.522 & 0.642 & 0.710 & 0.533 & 0.453 \\
\hline $\mathrm{RZ}$ & 0.595 & 0.633 & 0.758 & 0.626 & 0.463 \\
\hline SH & 0.565 & 0.629 & 0.756 & 0.544 & 0.541 \\
\hline SLD & 0.566 & 0.669 & 0.663 & 0.601 & 0.503 \\
\hline WW & 0.618 & 0.682 & 0.716 & 0.567 & 0.465 \\
\hline XGS & 0.543 & 0.620 & 0.708 & 0.636 & 0.564 \\
\hline $\mathrm{XT}$ & 0.564 & 0.651 & 0.668 & 0.540 & 0.465 \\
\hline XSD & 0.428 & 0.647 & 0.678 & 0.635 & 0.593 \\
\hline $\mathrm{XC}$ & 0.547 & 0.716 & 0.625 & 0.624 & 0.643 \\
\hline $\mathrm{ZPT}$ & 0.508 & 0.651 & 0.673 & 0.596 & 0.364 \\
\hline $\mathrm{ZP}$ & 0.611 & 0.629 & 0.696 & 0.673 & 0.851 \\
\hline $\mathrm{ZY}$ & 0.605 & 0.669 & 0.653 & 0.662 & 0.427 \\
\hline $\mathrm{ZT}$ & 0.549 & 0.612 & 0.682 & 0.606 & 0.569 \\
\hline ZLS & 0.564 & 0.607 & 0.582 & 0.603 & 0.463 \\
\hline
\end{tabular}

differences. The average precipitation in Beiru River generally showed negative trends in spring, summer and autumn and in annual series, except a slightly positive trend in winter. In Sha River, the average precipitation showed positive trends in spring, summer and winter and in annual series and a slightly negative trend was only found in autumn. In Li River, although negative trends for the precipitation series occurred in three seasons of spring, autumn, and winter, a positive trend was found in an annual series because the positive trend in summer was relatively significant. The results indicated that the annual precipitation series showed positive trends in the northern region and negative trends in the southern region.

3.3. R/S Analysis for Future Trends. The Hurst Exponent $(H)$ values estimated by $R / S$ analysis in monthly, seasonal, and annual scales were shown in Table 1 for precipitation series in catchment average, Table 4 and Figure 4 for individual station, and Figure 5 for three subcatchments. From Table 1, the $H$ values during March-May, September and October, and December were far larger than 0.5. It indicated trend reinforcing series for these months. The increase trends in March, May, and September and decrease trends in April, October, and December were enhanced. This trend reinforcing was found in spring and summer with an increasing trend and in autumn in a decreasing trend. The annual $H$ value was close to 0.5 , which indicated a randomness of the time series.

Table 4 and Figure 4 presented that the $H$ values for all precipitation series of the 38 rainfall stations were on the upper side of the value of 0.5 in summer, autumn, and winter. Because most of the trends were positive in summer and winter, it again validated that these positive trends were reinforced. From Figure 5, we can see that all the $H$ values of the annual and seasonal precipitation series in Beiru River were greater than 0.5 , which means the dependence of future trends on previous ones. In Sha River, in spite of the consistency of future trends in seasonal precipitation, the $H$ value of the annual time series was 0.420 , which referred to an antipersistent nature. In Li River, all of the $H$ values except the one in spring were found to be greater than 0.5 , indicating a continuous nature for the future precipitation. The results were similar to the analysis for the stations.

Figures 6(a) and 6(b) show the relationship between $Z$ and $H$ values, and between $\beta$ and $H$ values according to values in Tables 2 and 4 . The following results were obtained from Figures 6(a) and 6(b): (1) persistent exists ( $H>$ 0.5 or $<0.5)$ though the trend is not statistically significant $(Z<1.64)$; (2) when for the increasing trend $(Z>0$ or $\beta>0$ in Figures 6(a) and 6(b)), the greater the $Z$ values or $\beta$ values, the stronger the persistent; that is to say, the increasing trends will be reinforced in the future; (3) for the decreasing trends $(Z<0$ or $\beta<0$ in Figures 6(c) and 6(d)), the greater the absolute values of $Z$ or $\beta$, the stronger the persistent; that is to say, the decreasing trends will be reinforced as well; (4) both the slopes in Figures 6(c) and 6(d) were relatively smaller than the corresponding ones in Figures 6(a) and 6(b), indicating that the future changes of precipitation in the whole area will be stronger in positive trends than in negative trends.

\section{Conclusions}

In this paper, trends of precipitation were investigated using the linear regression method, the Mann-Kendall test, and the $R / S$ analysis based on daily data from 38 rainfall stations in the study area during the period 1951-2010 (Figure 3). The following conclusions were obtained.

The results show that the trends in precipitation were relatively not significant in catchment average even though 

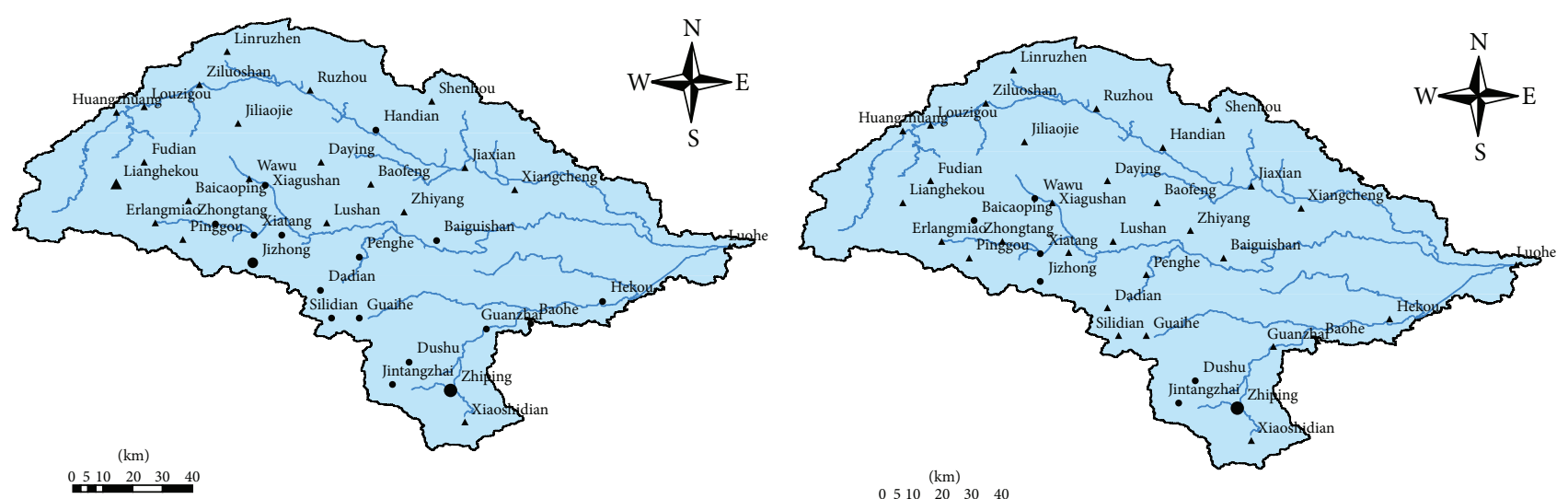

- $99 \%$ increase trend

- $90 \%$ increase trend

- Decrease not significant

- Increase not significant

- $95 \%$ decrease trend

— River system

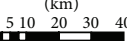

(a) Annual

- $95 \%$ increase trend

- Increase not significant
- Decrease not significant

River system
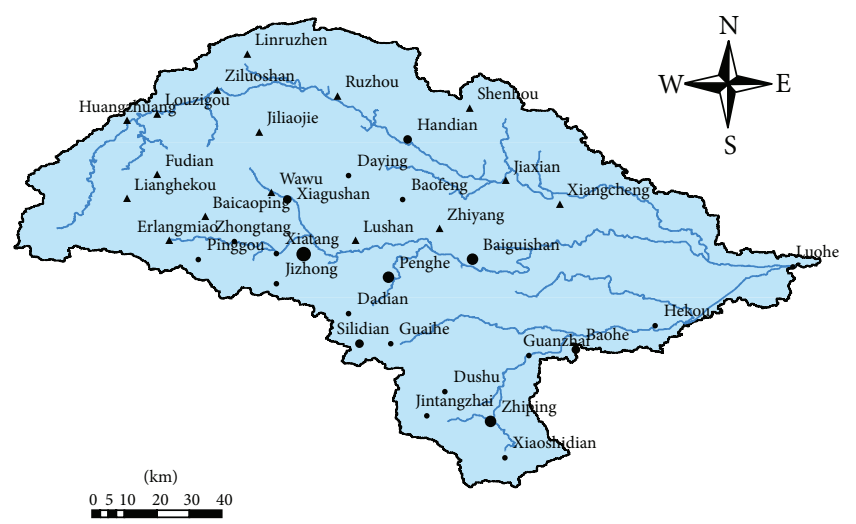

\begin{abstract}
- Increase not significant
- Decrease not significant

River system
\end{abstract}

(c) Summer

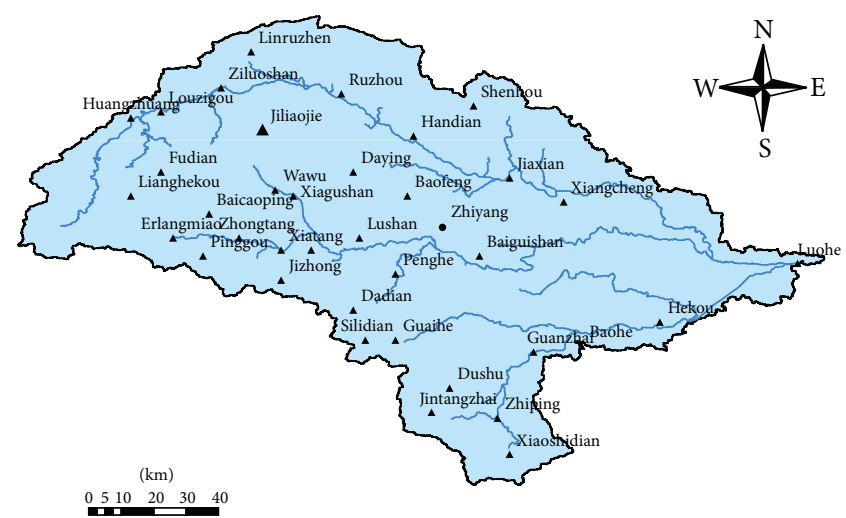

- Increase not significant

- Decrease not significant

- $\quad 95 \%$ decrease trend

River system

(d) Autumn

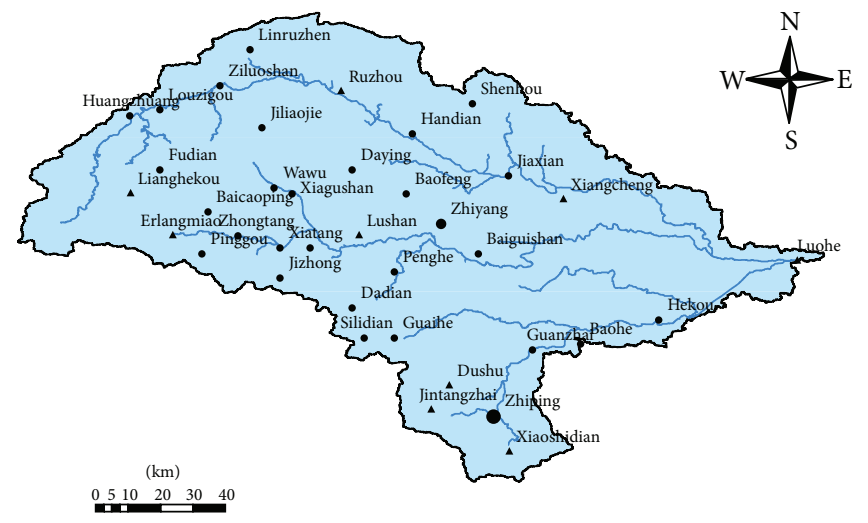

- $99 \%$ increase trend

- Decrease not significant

- $90 \%$ increase trend

River system

- Increase not significant

(e) Winter

FIGURE 3: Trends for annual and seasonal precipitation in the 38 stations during the period 1951-2010. 


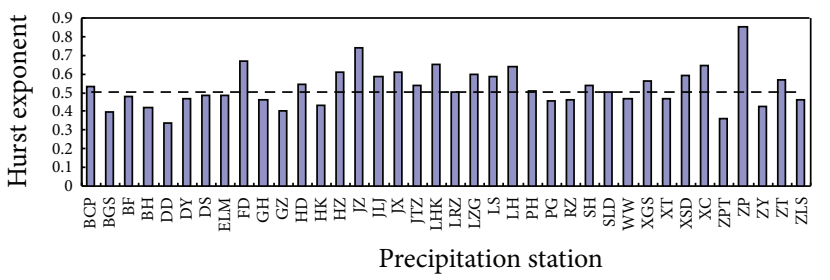

— Annual

--- Critical value

(a) annual

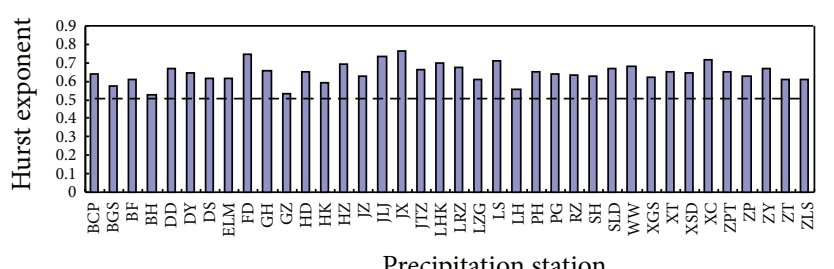

Precipitation station

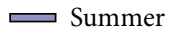

- - - Critical value

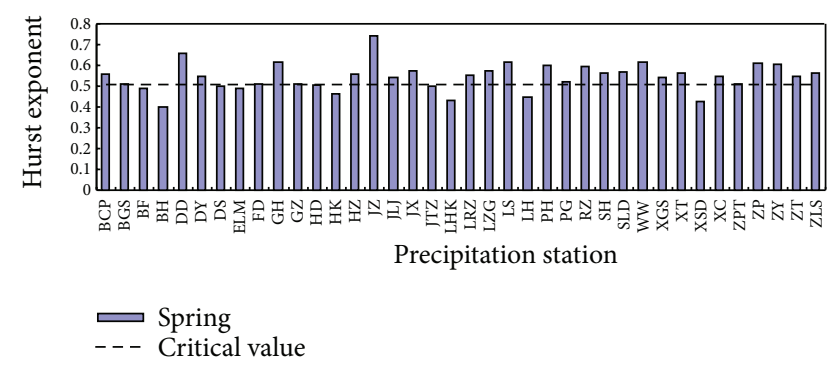

(b) Spring

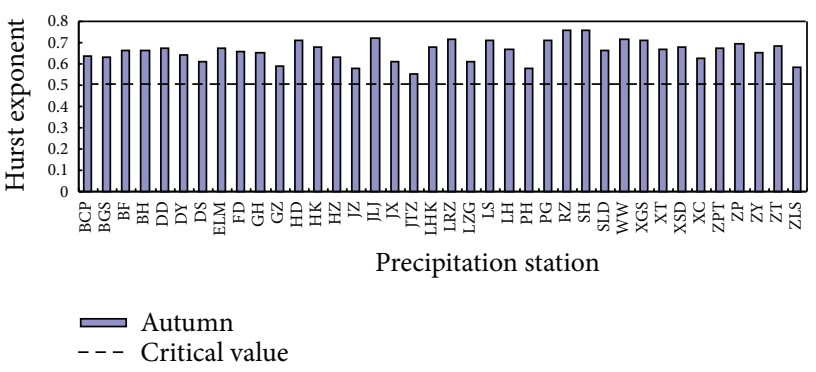

(d) Autumn

- - - Critical value

(c) Summer

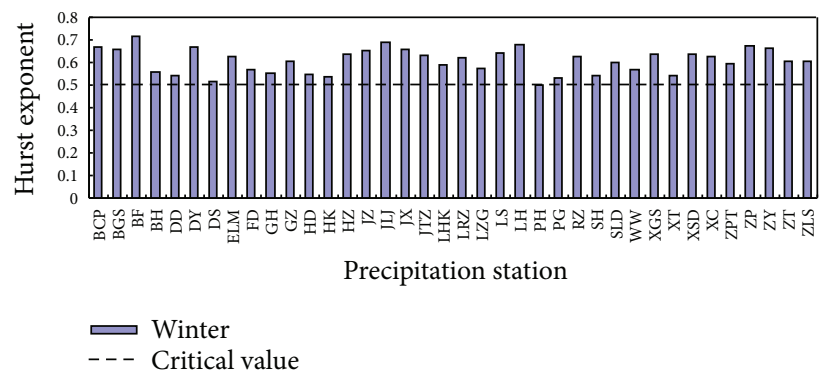

(e) Winter

FIGURE 4: Values of $H$ of the $R / S$ analysis for annual and seasonal precipitation in the 38 stations.

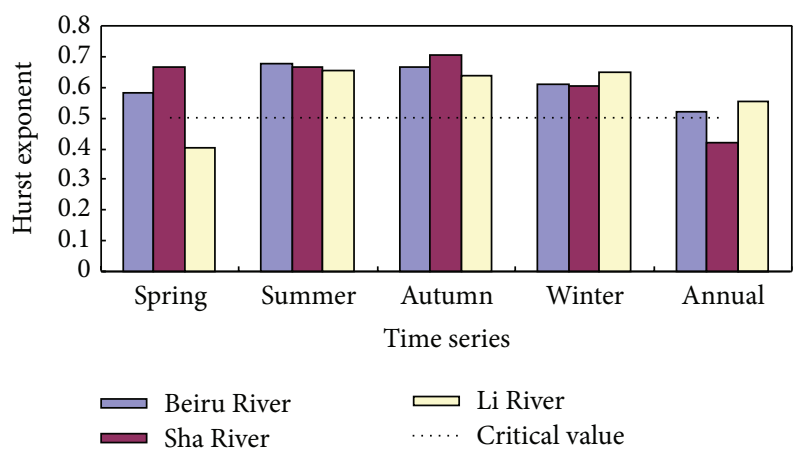

FIGURE 5: Values of $H$ of the $R / S$ analysis for annual and seasonal precipitation in three subcatchments. 


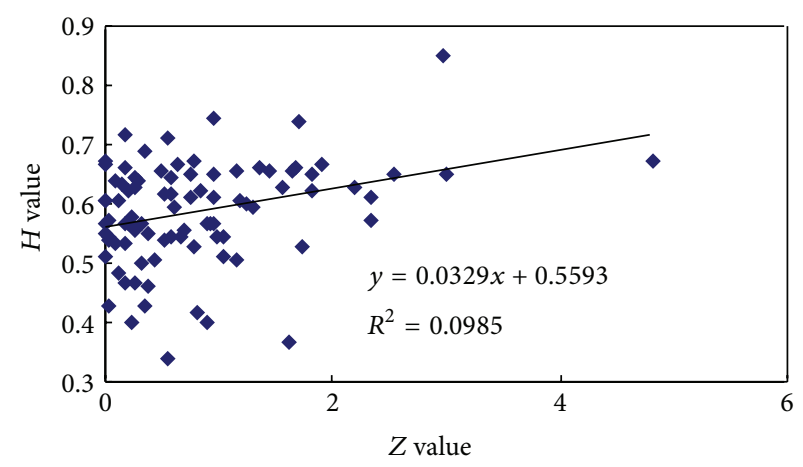

(a) $\mathrm{Z}>0$

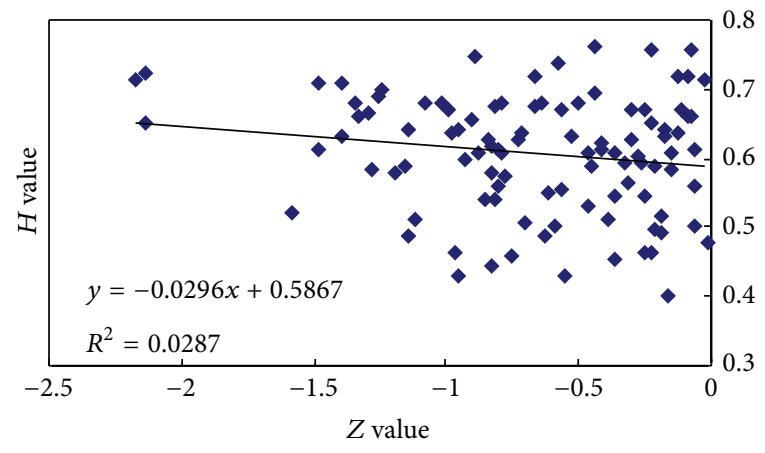

(c) $\mathrm{Z}<0$

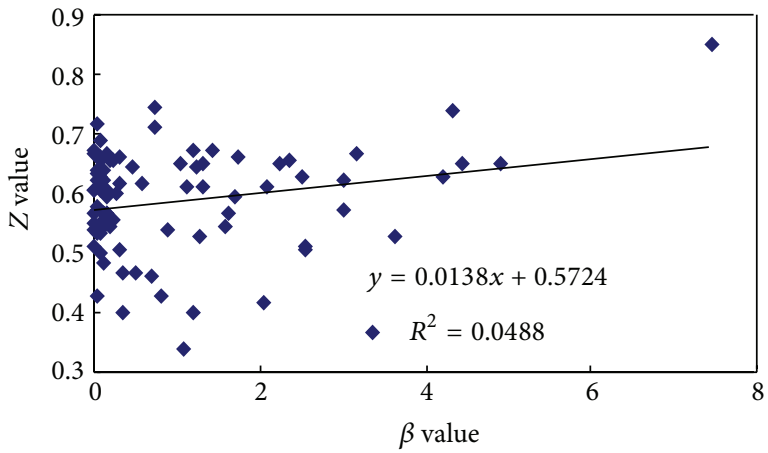

(b) $\beta>0$

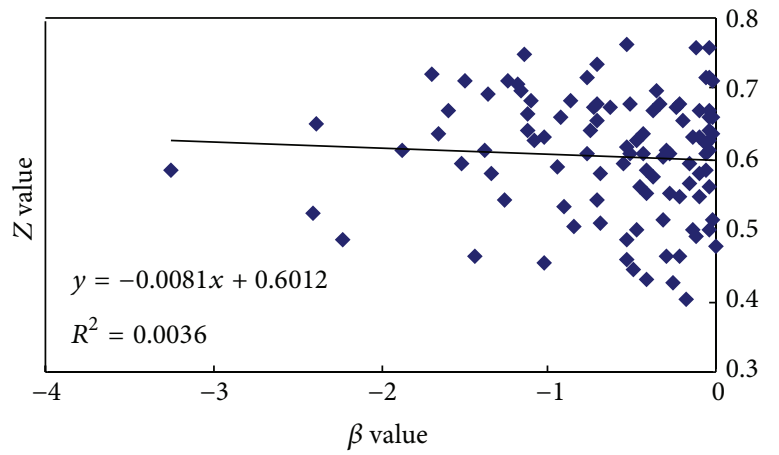

(d) $\beta<0$

FIGURE 6: The relationship analysis of $H-Z$ and $H-\beta$.

significant trends in some observation stations were found. The annual precipitation in the whole catchment represented a slightly increase trend in the past 60 years, with the rate of $0.042 \mathrm{~mm} /$ year. Precipitation series in spring and autumn presented decrease trend in a rate of -0.011 and $-0.365 \mathrm{~mm} /$ year, respectively, and presented increase trend in a rate of 0.241 and $0.051 \mathrm{~mm} /$ year, respectively.

Increase trend in summer is relatively significant. Significant trends in summer account for $21 \%$ of the stations. Meanwhile, most of stations with significant increase trends were located in the downstream of the catchment. This increase trends in summer, particularly in the plain area of downstream station, would result in increase of flood occurrences in the study region.

According to calculated Hurst Exponent values, the future precipitation in January and annual series was anticipated to be antipersistent with the past, the rest time series showed persistent trends in the future, and the future precipitation trends were enhanced in all of the 38 rainfall stations in summer, autumn, and winter. The majority of the stations with an antipersistent nature in annual series were concentrated in the central area of the catchment, which probably related to the three large reservoirs (Zhaopingtai, Baiguishan, and Gushitan) in the central region. The three reservoirs were all started to construct in the year 1958 and completed in the 1960s.

The relationships of $H-Z$ and $H-\beta$ of the 38 stations indicated that persistent exists though the trend is not statistically significant $(Z<1.64)$. Meanwhile, the increase and decrease trends will be reinforced in the future as the increase and decrease trends tend to be more and more significant. Generally, the future changes of precipitation in the whole area will be stronger in positive trends than in negative trends.

However, as the data series are not long enough, the question of whether we are facing long-term climatic trends or whether the observed trends are only a part of longterm variability remains unanswered, and the understanding of influence of the reservoirs is not thorough clearly. In addition, it is also suggested to explore other hydrological and meteorological variables available in the study area. Further studies would be interesting to investigate the interrelationship between different variables.

\section{Acknowledgments}

The first author thanks the following financial support: Major Program of National Natural Science Foundation of China (51190091); the National 973 Project under Grant no. 2010CB951102; and the National Natural Science Foundation of China (no. 41001011/40901015/41101018).

\section{References}

[1] V. Kumar and S. K. Jain, "Trends in seasonal and annual rainfall and rainy days in Kashmir Valley in the last century," Quaternary International, vol. 212, no. 1, pp. 64-69, 2010. 
[2] Y. F. Zhang, D. X. Guan, C. J. Jin, A. Z. Wang, J. B. Wu, and F. G. Yuan, "Analysis of impacts of climate variability and human activity on streamflow for a river basin in northeast China," Journal of Hydrology, vol. 410, no. 3-4, pp. 239-247, 2011.

[3] P. G. Oguntunde, B. J. Abiodun, and G. Lischeid, "Rainfall trends in Nigeria, 1901-2000," Journal of Hydrology, vol. 411, no. 3-4, pp. 207-218, 2011.

[4] I. A. Tošić, "Spatial and temporal variability of winter and summer precipitation over Serbia and Montenegro," Theoretical and Applied Climatology, vol. 77, no. 1-2, pp. 47-56, 2004.

[5] O. I. Abdul Aziz and D. H. Burn, "Trends and variability in the hydrological regime of the Mackenzie River Basin," Journal of Hydrology, vol. 319, no. 1-4, pp. 282-294, 2006.

[6] T. Jiang, B. D. Su, and H. Hartmann, "Temporal and spatial trends of precipitation and river flow in the Yangtze River Basin, 1961-2000," Geomorphology, vol. 85, no. 3-4, pp. 143-154, 2007.

[7] H. Tabari and P. H. Talaee, "Temporal variability of precipitation over Iran: 1966-2005," Journal of Hydrology, vol. 396, no. 3-4, pp. 313-320, 2011.

[8] V. Mosmann, A. Castro, R. Fraile, J. Dessens, and J. L. Sánchez, "Detection of statistically significant trends in the summer precipitation of mainland Spain," Atmospheric Research, vol. 70, no. 1, pp. 43-53, 2004.

[9] M. Cislaghi, C. de Michele, A. Ghezzi, and R. Rosso, "Statistical assessment of trends and oscillations in rainfall dynamics: analysis of long daily Italian series," Atmospheric Research, vol. 77, no. 1-4, pp. 188-202, 2005.

[10] P. Coulibaly, "Spatial and temporal variability of Canadian seasonal precipitation (1900-2000)," Advances in Water Resources, vol. 29, no. 12, pp. 1846-1865, 2006.

[11] Q. Liu, Z. F. Yang, and B. S. Cui, "Spatial and temporal variability of annual precipitation during 1961-2006 in Yellow River Basin, China," Journal of Hydrology, vol. 361, no. 3-4, pp. 330-338, 2008.

[12] M. Ellouze, C. Azri, and H. Abida, "Spatial variability of monthly and annual rainfall data over Southern Tunisia," Atmospheric Research, vol. 93, no. 4, pp. 832-839, 2009.

[13] P. T. Nastos and C. S. Zerefos, "Spatial and temporal variability of consecutive dry and wet days in Greece," Atmospheric Research, vol. 94, no. 4, pp. 616-628, 2009.

[14] M. Afzal, M. G. Mansell, and A. S. Gagnon, "Trends and variability in daily precipitation in Scotland," Procedia Environmental Sciences, vol. 6, pp. 15-26, 2011.

[15] M. Cannarozzo, L. V. Noto, and F. Viola, "Spatial distribution of rainfall trends in Sicily (1921-2000)," Physics and Chemistry of the Earth, vol. 31, no. 18, pp. 1201-1211, 2006.

[16] K. H. Hamed, "Trend detection in hydrologic data: the MannKendall trend test under the scaling hypothesis," Journal of Hydrology, vol. 349, no. 3-4, pp. 350-363, 2008.

[17] I. Pal and A. Al-Tabbaa, "Trends in seasonal precipitation extremes-an indicator of 'climate change' in Kerala, India," Journal of Hydrology, vol. 367, no. 1-2, pp. 62-69, 2009.

[18] H. Q. Wang, M. S. Zhang, H. Zhu, X. Y. Dong, Z. Yang, and L. H. Yin, "Hydro-climatic trends in the last 50 years in the lower reach of Shiyang River Basin, NW China," Catena, vol. 95, pp. 33-41, 2012.

[19] X. L. Yang, L. R. Xu, K. K. Liu, C. H. Li, J. Hu, and X. H. Xia, "Trends in temperature and precipitation in the Zhangweinan River Basin during the last 53 Years," Procedia Environmental Sciences, vol. 13, pp. 1966-1974, 2012.
[20] H. Hurst, Long Term Storage Capacity of Reservoirs, vol. 6, Transactions of the American Society of Civil Engineers, 1951.

[21] H. J. Li, Z. Q. Xia, J. Zhang, and N. Zhang, "Analysis of time series of annual precipitation in Irtysh River Basin," Water Resources Protection, vol. 26, no. 5, pp. 29-32, 2010.

[22] A. Montanari, R. Rosso, and M. S. Taqqu, "Some long-run properties of rainfall records in Italy," Journal of Geophysical Research D, vol. 101, no. 23, pp. 29431-29438, 1996.

[23] G. Y. Wang and S. B. Dai, "Variation of water resource and its quality of Huaihe River in the past half century," Journal of Anhui Normal University (Natural Science), vol. 31, no. 1, pp. 7578, 87, 2008 (Chinese).

[24] S. Wang, W. S. Xie, W. A. Tang, Y. Tao, and X. Ding, "Change characteristics of day and night precipitation in Huaihe River Basin in 1961-2009," Chinese Journal of Ecology, vol. 30, no. 12, pp. 2881-2887, 2011 (Chinese).

[25] W. Q. Xing, W. G. Wang, Y. Q. Wu, and G. Y. An, "Change properties of precipitation concentration in Huaihe River Basin," Water Resources and Power, vol. 29, no. 5, pp. 1-5, 2011 (Chinese).

[26] C. H. Xu, Y. Luo, and Y. Xu, "Projected changes of precipitation extremes in river basins over China," Quaternary International, vol. 244, no. 2, pp. 149-158, 2011.

[27] X. P. Wang, "Characteristics analysis of rainfall in the upper reaches of the Shaying River Basin," Hydrology, vol. 20, no. 1, pp. 53-55, 2000 (Chinese).

[28] H. Tabari, S. Marofi, and M. Ahmadi, "Long-term variations of water quality parameters in the Maroon River, Iran," Environmental Monitoring and Assessment, vol. 177, no. 1-4, pp. 273-287, 2011.

[29] J. Peng, Z. H. Liu, Y. H. Liu, J. S. Wu, and Y. N. Han, "Trend analysis of vegetation dynamics in Qinghai-Tibet Plateau using Hurst Exponent," Ecological Indicators, vol. 14, no. 1, pp. 28-39, 2012.

[30] H. Tabari and P. H. Talaee, "Analysis of trends in temperature data in arid and semi-arid regions of Iran," Global and Planetary Change, vol. 79, no. 1-2, pp. 1-10, 2011.

[31] J. M. Mithell, B. Dzerdzeevskii, H. Flohn et al., "Climatic change. (Report of a working group of the Commission for Climatology)," WMO Technical Note No. 79, World Meteorological Organization, 1966.

[32] K. Chaouche, L. Neppel, C. Dieulin et al., "Analyses of precipitation, temperature and evapotranspiration in a French Mediterranean region in the context of climate change," Comptes Rendus Geoscience, vol. 342, no. 3, pp. 234-243, 2010.

[33] M. G. Kendall, Rank Correlation Methods, Griffin, London, UK, 1975.

[34] Z. Sánche, J. E. Trinidad, and P. J. García, "Some comments on Hurst exponent and the long memory processes on capital markets," Physica A, vol. 387, no. 22, pp. 5543-5551, 2008.

[35] X. L. Wang, B. Q. Hu, and J. Xia, "R/S analysis method of trend and aberrance point on hydrological time series," Engineering Journal of Wuhan University, vol. 35, no. 2, pp. 10-12, 2002 (Chinese).

[36] Y. S. Yu and X. W. Chen, "Analysis of future trend characteristics of hydrological time series based on R/ S and Mann-Kendall methods," Journal of Water Resources \& Water Engineering, vol. 19, no. 3, pp. 41-44, 2008 (Chinese).

[37] Q. M. Bu, J. Bi, Z. W. Yuan, and L. Huang, "R/S method for evaluation of pollutant time series in environmental quality assessment," Water Science and Engineering, vol. 1, no. 4, pp. 82$88,2008$. 


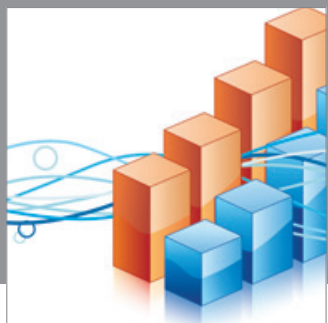

Advances in

Operations Research

mansans

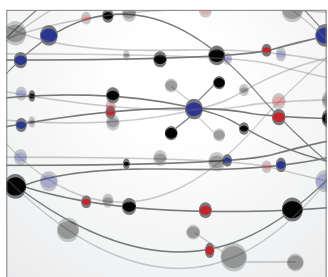

The Scientific World Journal
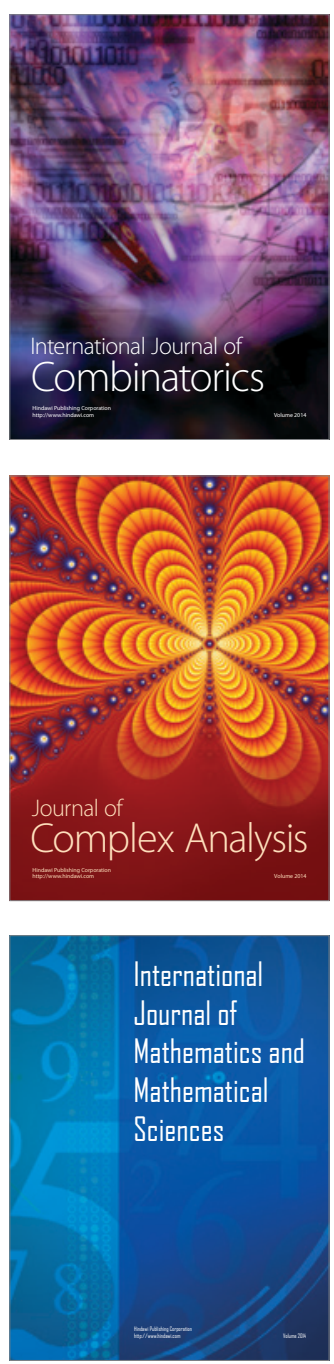
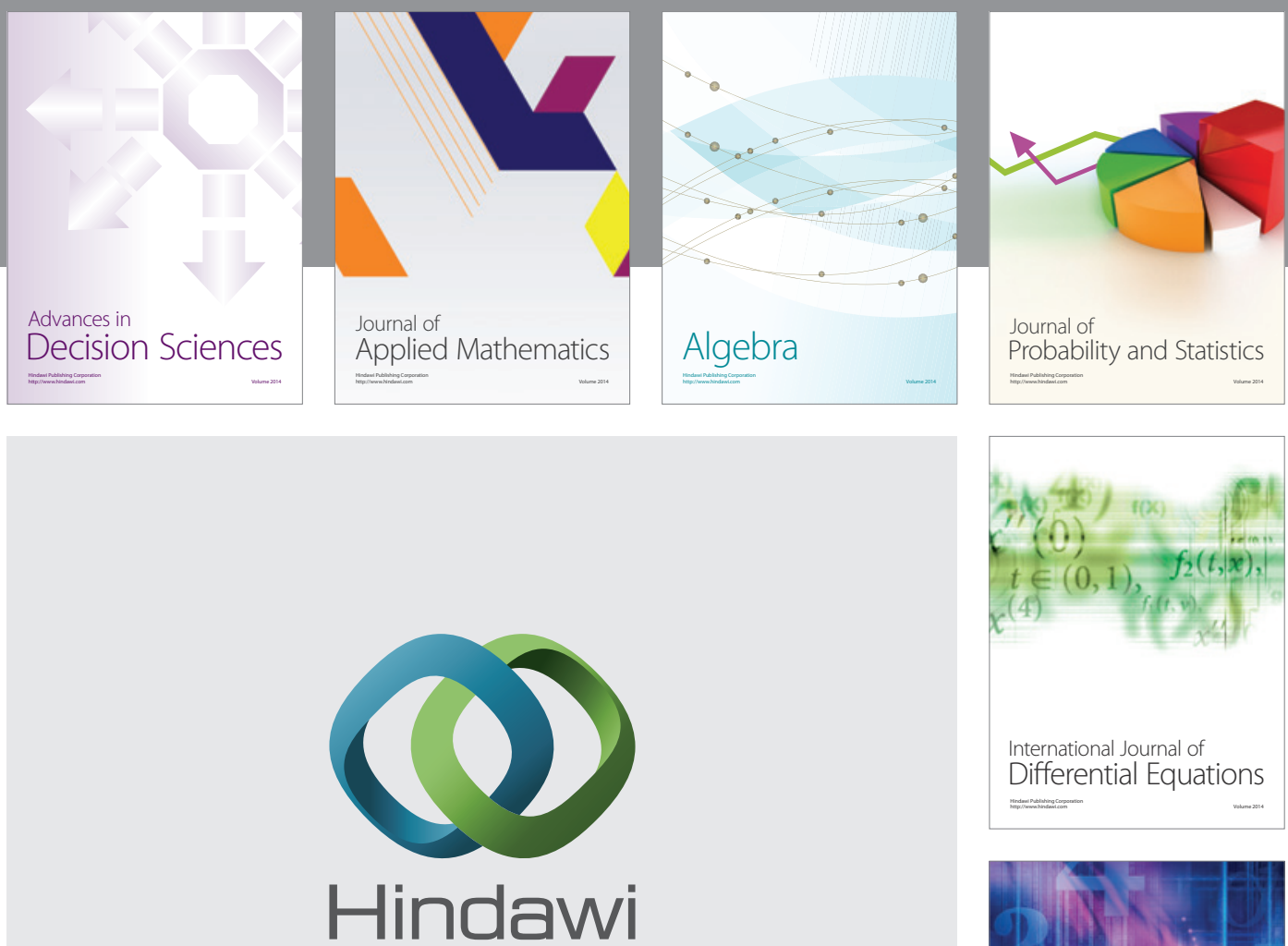

Submit your manuscripts at http://www.hindawi.com
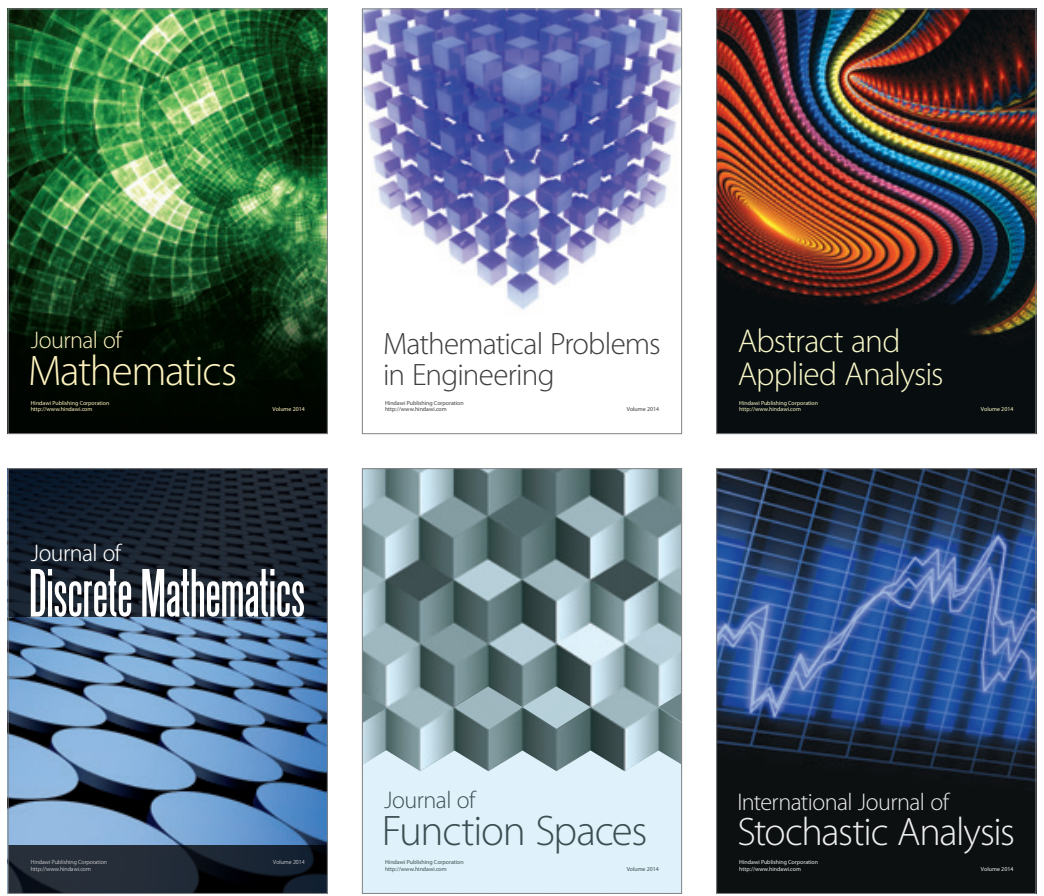

Journal of

Function Spaces

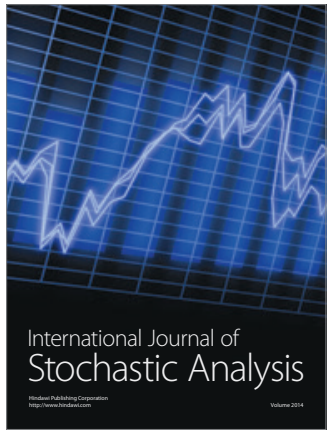

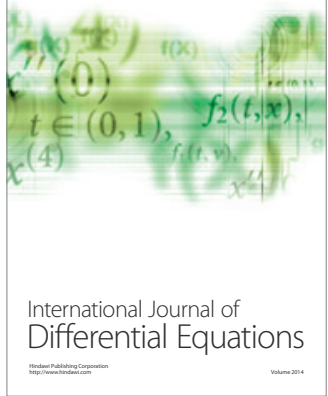
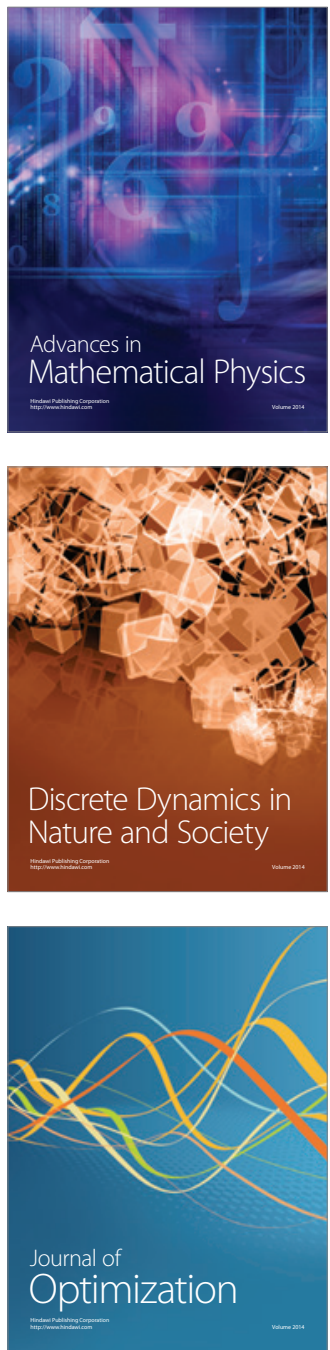